\title{
ALGUMAS CONSIDERAÇÕES EM TÔRNO DE UMA NOVA LIÇÃO DO PADRE SERAFIM LEITE RELATIVA A FUNDAÇÃO DE SÃO PAULO.
}

Lamentamos sinceramente ter que submeter de novo à crítica, que não poderá ser complacente porque busca a verdade, mais um escrito do ilustre autor da monumental História da Companhia de Jesús no Brasil, relativo à fundação de São Paulo, publicado simultâneamente a 12 de setembro último em "O Estado de São Paulo" e no "Jornal do Comércio" do Rio de Janeiro, sob o título: Nóbrega no dia 25 de janeiro de 1554. Quem cala consente, diz o rifão popular. Calar-se aqui seria recuar de uma atitude que assumimos refletidamente, quando discordamos do Padre Serafim Leite, ao tecer "considerações em tôrno de um livro" seu "sôbre a fundação de. São Paulo" (1).

Se é que compreendemos alguma coisa do que aí quis dizer o sempre respeitável historiador português, o que pretendeu demonstrar nesse artigo é que, a 25 de janeiro de 1554, - contra o que até hoje todos vimos acreditando, inclusive o próprio Padre Serafim Leite (2) - esteve presente em Piratininga o Padre Manuel da Nóbrega ao ser fundado o Colégio. Sendo êste a célula-mater da cidade de São Paulo, mais um título possuiria Nóbrega para que os seus panegiristas o considerassem "o fundador" de nossa metrópole.

Ora, se a História se faz com documentos, é óbvio que não. se refaz sem novos documentos, ou pelo menos sem nova interpretação de documentos mal interpretados. Tudo isso, porém, há de ser feito com a maior clareza e absoluta sinceridade de quem, reverente e ostensivamente, se descobre perante a verdade mal esta assoma no horizonte.

Em se tratando da presença do Padre Manuel da Nóbrega em Piratininga a 25 de janeiro de 1554, silenciam todos os textos his-

\footnotetext{
(1). - Revista de História, número 18 , páginas 483 a 489.

(2). - "O exame objetivo dos documentos dão-nos estas certezas: no dia 25 de janeiro de 1554 estavam. (no campo de Piratininga) os Padres Manuel de Paiva, Afonso Braz e o Irmão José de Anchieta. Estes são os fundadores. Quem mais"? Serafim Leite, História, volume I, página 277.
} 
tóricos existentes. Não descobriu ainda o notável rebuscador de arquivos, que é o Padre Serafim Leite, o primeiro documento que registre êsse fato histórico. $E$ perante tal silêncio, haveremos forçosamente que admitir um dêstes dois fatos: primo, a de que o vice-provincial esteve de fato ausente aqui nessa data; secundo, ou que, para os cronistas da Companhia de Jesús, a começar por Anchieta, tão obscura se apresentava a figura de Nóbrega, que não valia o esfôrço de uma simples menção do seu nome, quando se referiram ao acontecimento.

Na falta absoluta, portanto, de um único texto que diga ter estado presente o Padre Manuel da Nóbrega à fundação do Colégio, como se houve o ilustre historiador para tentar a demonstração do "fato" històricamente? Valeu-se de dois argumentos pueris que assim se resumem: primo, esteve antes. Esteve depois. Logo esteve também nessa data; secundo, diz Serafim Leite, conheço sobejamente o caráter de Nóbrega. Ora êsse caráter jamais permitiria estivesse êle ausente aqui a 25 de janeiro de 1554. Logo esteve presente.

Estamos assim evidentemente afastados do campo sereno da História. Sim, porque prescindir da documentação e substituí-la por deduções de valor meramente conjetural, jamais foi processo usual de fazer História. Nada mais fácil que retorquir a tais argumentos: primo, há documentos que provam a presença de Nóbrega antes e depois. Não há documento nenhum que prove a sua presença aqui a 25 de janeiro de 1554. Logo aqui não esteve êle nesse dia; secundo, o conhecimento que diz ter $\dot{0}$ Padre Serafim Leite do caráter de Nóbrega o obriga a concluir que êste esteve em São Paulo na data referida. Ora, cá não esteve êle nesse dia. Logo o conhecimento que diz ter o Padre Serafim Leite do caráter de Nóbrega vale muito pouco.

Eis a que se reduz - e nos pesa dizemo-lo mais uma vez, ter que chegar a conseqüências tão em desacôrdo com a autoridade de pessoa tão respeitável, diante de cuja obra nos inclinamos reverentes -, eis a que se reduz a réplica do Padre Serafim Leite às ,contestações que the tem sido opostas, com outra espécie de argumentos e em nome de uma lógica bem mais consistente do que a sua.

Afirma o Padre Simão de Vasconcelos que foi por Nóbrega enviado o Padre Manuel de Paiva, à frente de um grupo de jesuítas para fundarem aqui o Colégio de São Paulo, coisa que realizaram a 25 de janeiro de 1554. Tal afirmação, como aliás tôda a exposição dos acontecimentos dessa época, sobretudo o que se refere à pessoa de Nóbrega, vai buscá-la Vasconcelos na documentação do itempo, nos escritos especialmente de Anchieta. Cita expressamen- 
te, e mais de uma vez, os seus Apontamentos (3), preciosissimo: testemunho de quem presenciou os fatos, possuia memória excepcional e incontestável retidão de consciência.

Nenhum documento existe, por outro lado, que refute esta afirmativa particular de Vasconcelos. Todos os textos existentes. (Antônio de Matos, Quirício Caxa, a Historia de la fundacion del Colegio del Rio de Henero, João Polanco, a Breve informação do Brasil de Anchieta, a sua Quadrimestre de maio a setembro) não só não contradizem, mas ao contrário, favorecem a versão: se "mandou", não veio ["quem quer vai, quem não quer manda" (4)]. De tudo se conclui, sem o menor esfôrço e sem vislumbre de sofisma, que, até prova certa em contrário, continua perfeitamente válida a mesma afirmativa de Simão de Vasconcelos.

Repisando o assunto em tela, será exato que Vasconcelos tenha forjado, como quer o Padre Serafim Leite, a segunda consulta havida em São Vicente e da qual resultou a decisão de enviar (de São Vicente... De onde afinal quereria que os enviasse?) para a Aldeia de Piratininga os estudantes da Companhia, nomeando-se então mestre dêles o Irmão José de Anchieta? Será verdade, como diz o Padre Serafim, que Vasconcelos "viu que houve uma consulta em São Vicente, narrada na carta de 15 de junho de 1553, e como. vinha bem à sua arquitetura, colocou-a em fins de dezembro ou comêço de janeiro, antes da subida dos Irmãos?".

Se o padre Vasconcelos leu essa carta de 15 de junho, leu também nela que a resolução tomada nessa consulta fôra loğo delpois. estorvada pessoalmente pelo Governador Geral Tomé de Souza (5). Sabe o Padre Serafim (e por que não devia saber Vasconcelos?) que, na carta de 10 de março, escrita ao Padre Simão Rodrigues, mencionava o Padre Nóbrega a partida do Governador (6), claramente relacionada com a proibição ao seu projeto de ir ao $\mathrm{Pa}$ raguai, projeto assentado desde o mês de fevereiro. Logo a consulta precedeu essa data de 10 de março. Como teima, pois, o.

(3). - "Tudo isto nesta mesma forma achei escrito pelo Venerável Padre José de. Anchieta, de sua própria mão em certos Apontamentos, que em meu poder. tenho": Vida do Padre João de Almeida, página 73. "E advirto aqui, quenas coisas particulares dêste nosso pai da Província e seus companheiros, se-guirei com principal cuidado uns apontamentos, que em meu poder tenho, do. venerável Padre José de Anchieta, escritos de sua própria mão e letra... E. por serem de tão autorizado varão, contemporâneo, amigo e companheiro seu, são. dignos de todo o crédito, e da verdade que nesta matéria se pode desejar, e eu. sempre procurei seguir em tôda ela". Crónica, etc., L. I., n. 07 .

(4). - Padre Hélio A. Viotti S. J., Nóbrega ausente em Piratininga, no suplemento. do "Correio Paulistano" de 6 de setembro de 1953.

(5). - Novas Cartas Jesuiticas, página 41. Note-se a identidade de expressão cóm 6 . que escrevera a 10 de março de 1553 o Irmão Anônimo: "O Padre Nóbrega determinou ir pela terra dentro entre os gentios e levar alguns Irmāos para os: ensinar e ajudar a conhecer ao seu Criador, do qual andam tão longe, e com a ajuda do Senhor fazer entre êles uma cidade, fazendo-os cristãos; mas o. Governador o estorvou". . Padre Serafim Leite, Nóbrega o a fundaçāo de Sãor Paulo, página 18 .

(6). - Padre Serafim Leite, Nóbrega e a fundagäo do São Paulo; página. 21. 
Padre Serafim em afirmar que a mesma é anterior apenas à data de 15 de junho? Para que mais fàcilmente os seus leitores acreditem na história da falsificação praticada por Simão de Vasconcelos?

Não desejamos atribuir ao consagrado autor da Histótia da Companhia de Jesús no Brasil o propósito definido de induzir em êrro aos seus leitores, nem aceitar que a "sua maneira" seja exatamente aquela que procura imputar a Simão de Vasconcelos. Como explicar, entretanto, que, ainda a respeito dêste caso, passe em silêncio o documento aduzido pelo seu confrade Padre Hélio Abranches Viotti? Eis o que êste escreve: "No De prima Collegii Fluminis Januarii Institutione, trabalho redigido quarenta e pouco anos mais cêdo (1619-1621, Serafim Leite, I, XXVII) que a Crônica da Companhia de Jesús do Estado do Brasil (1662), dera já notícia dessa consulta ou deliberação, na qual se assentou a fundação do Colégio dos jesuítas em Piratininga, o Padre Antônio de Matos, homem de capacidade invulgar que ocupou os maiores cargos na Província do Brasil".

"Na vila de São Vicente, - escreve Antônio de Matos -, estabeleceu o Padre Leonardo Nunes, um ensaio do primeiro Colégio que houve no Brasil, reunindo em regime de internato bom número de rapazes indígenas, que eram cuidadosamente educados, não em práticas de vida monástica, mas sim em exercícios escolares, aprendendo os rudimentos da doutrina e as primeiras letras. Trouxe Nóbrega à discussão (vertit... in controversiam) se se devia continuar aí êsses estudos, ou se pelo contrário convinha que se fizessem na vila de São Paulo (a que chamavam Piratininga").

"Pareceu então aos Padres que o Colégio se deveria mudar para lá, uma vez que, o ar sendo aí mais puro e o clima mais ameno, seria êsse lugar mais favorável para os estudos. Além disso bem mais abundante era lá nesse tempo, para o zêlo dos evangelizadores, a seara das almas. Para primeiro mestre de humanidades em Piratininga foi assim nomeado o Padre José de Anchieta que, embora não fôsse ainda sacerdote, era desde então reputado por santo. Com alguns irmãos, dos quais doze estudantes, se encaminhou êle para lá, passada a festa da Epifania, no ano de 1554" (7).

Eis outro alvo, sôbre o qual, modifficando lalça e deriva deve o Padre Serafim Leite concentrar o fogo de sua grossa artilharia: - Padre Antônio de Matos. Naturalmente outras vítimas deverá fazer ainda, para recompor a história da fundação de São Paulo, em holocausto à maior glória do seu conterrâneo, Padre Manuel da Nóbrega. Não é possível que the passe sob a mira, em

(7). - Padre Hélio A. Viotti S. J., Nova consulta em São Vicente, artigo no suplemento do "Correio Paulistano" de 23 de agôsto de 1953, que em nota, indica - capítulo 2.0 da obra citada: Qui e Societate Jesu primi Divi Vicentii in Brasilia oppidum appulerint. 
Branca nuvem, o secretário de Santo Inácio de Loiola, João Polanco, que no seu Chronicon Societatis Jesu resumiu as cartas que chegavam do Brasil. Afirma êste que Nóbrega enviou (de São Vicente, é evidente) para a Aldeia de Piratininga os fundadores do Colégio (8). Afirma que a residência oficial de Nóbrega, no ano de 1554, não era em Piratininga, como quer o Padre Serafim Leite, mas sim em São Vicente (9).

Escreveu o notável historiador português na sua valiosa $H$ istória da Companhia de Jesús no Brasil que, no dia 25 de janeiro de 1554, presentes, com certeza, em Piratininga estavam sòmente os Padres Manuel de Paiva, Afonso Braz e o Irmão José de Anchieta. "Estes são os fundadores", diz Serafim Leite. E, mais abaixo, acrescenta: "Nóbrega é... o primeiro e principal fundador de São Paulo" (10). Atualmente pensa e, no artigo que estamos criticando, tenta demonstrar, - se é que compreendemos o que nesse artigo quis dizer o Padre Serafim, - o seguinte: quem esteve, com certeza absoluta, em São Paulo, a 25 de janeiro de 1554, foi o Padre Manuel da Nóbrega; não se sabe se também Manuel de Paiva. Ele, Nóbrega, é o fundador, como dizem os franceses, toult court e mais ninguém! Se não é isso o que quis dizer, por que deuse ao trabalho de escrever sôbre Nóbrega no dia 25 de janeiro de 1554 ?

Como estamos vendo, são afirmações contraditótias. Os documentos, entretanto, para umas e outras, para as primeiras como para as últimas afirmações, são absolutamente as mesmos. Não foi, pois, objetivo, o exame que então fêz dos documentos (11). O que variou, foi portanto a interpretação dos mesmos, se é que se pode interpretar um documento que não existe! Onde antes leu sim, agora lê não. Onde antes via não, agora enxerga sim. Duas atitudes diametralmente opostas. E quem sabe se as últimas interpretações serão definitivas? Só o tempo poderá responder a esta pergunta.

Cabe agora examinar aqui a segunda parte do artigo do $\mathrm{Pa}-$ dre Serafim Leite, na qual tertta provar que a afirmativa de Vasconcelos, que conhecemos sôbre as pessoas presentes ao ato da fundação do Colégio, não pode ser verdadeira. E por que estrada se envereda para tentar provar o acêrto dessa sua opinião? Destruindo a argumentação que acabamos de expor? Absolutamente. Ladeando tudo isso, saindo pela tangente, para recorrer à ironia que é sempre fácil: garante o cronista que viu, através de sucessivas metamorfoses, como de uma larva de mosquito surgiu por fim um

\footnotetext{
(8). - Chronicon Societatis Jesu, IV, página 612. Padre Hélio A. Viotti S. J., loc. cit., 23-VIII-53.

(9). - Chronicon Societatis Jesu, IV, página 612, idem, ibidem

(10). - Serafim Leite, História, etc., vol. I, página 277.

(11). - "O exame objectivo dos documentos dão-nos (sic) estas certezas", Serafim Leite, História, etc., vol. I, página 277.
} 
beija-flor... Erro e simplicidade evidente! Não merece fé, por-: tanto, o cronista ao fazer aquela afirmação. Mas também o Padre. Manuel da Nóbrega acreditou nas lendas sobrenaturais do Novo: Mundo, tanto assim que se refere às amazonas na carta de 15 de junho de 1553 (12).

Não vamos mobilizar aqui os transformistas contemporâneos para com êles isentar de culpa Simão de Vasconcelos. Quanto ao. êrro, de que se trata, estamos agora perfeitamente de acôrdo com o erudito historiador pọrtuguês. Não porém quanto à conseqüência que daí pretende inferir. Ainda uma vez, afastados do campo se--. reno da História, pisamos em cheio no terreno da Lógica. Aí ouvimos seu protesto: a conclusão se estende a muito mais do que as: premissas podem consentir.

De que errasse o Padre Vasconcelos, como já admitimos, nas:suas superficiais, intermitentes, cândidas observações zoológicas, pasmado perante o ineditismo da exuberante flora e fauna do Novo Mundo, que até hoje nos escondem umas tantas surprêsas, não se" segue absolutamente que a sua exposição de acontecimentos hu-manos, por êle conhecidos através de documentos históricos, seja necessàriamente destituida de qualquer valor crítico. Portanto sim-plesmente extravagante a conclusão a que pretende ter chegado o. emérito Pađre Serafim Leite.

Bem mais admissível, portanto, nos parece, o dislate do velho: cronista da Companhia de Jesús, do que vir-nos agora o atual eilustre historiador jesuíta, Padre Dr. Serafim Leite, contra a voz. dos documentos ou apesar de seu significativo silêncio, deduzir de. seu conhecimento pessoal do caráter de Nóbrega, de quem o sepa-ra afinal o longo lapso de quatrocentos anas, o fato històricamente certo da sua estada em Piratininga a 25 de janeiro de 1554. Ou: ainda, dos erros cometidos por Vasconcelos, extrair o atestado de

\footnotetext{
(12). - Embora o descobrimento do Novo Mundo, em parte, fôsse uma consequiência do.. Renascimento, os colonizadores - aqui incluimos os jesuítas e outras ordens. religiosas -, ainda arreditavam piamente nas lendas e superstições medievais ; referentes ao Mar Tenebroso (Atlântico), ilhas e terras do Ocidente. Colombo, por exemplo, na sua primeira viagem admitiu a existência de homens com cauda, em Cibau; na segunda viagem disse que numa ilha de nome Madanina, os habitantes eram só mulheres solitárias; na terceira sustentou que o Paraíso Terrestre devia ficar nas proximidades do delta do Orenoco. Cortés também disse que numa ilha, que hoje nada mais é que a baixa Califórnia, a populaçāo era constituída sòmente de mulheres. Vespucci na sua viagem à América em 1499-1500, disse que esteve numa ilha, hoje identificada. como a Curaçau, habitada por gigantes. Essa opinião do Florentino foi perfilhada por Diego de Ordaz. Cortés, mais de uma vez organizou expedições para encontrar a região das amazonas. Nuno Guzmán, ao fugir da justiça espanhola,.. chefiou uma expedição em direção a noroeste do México, em busca das ama... zonas. Todos acreditavam na Fonte Eterna da Juventude, a ponto de Pedro ... Martyr de Angleria a isso fazer referência nas suas Décadas. Ả procura dessa. fonte partiu Ponce de Leon, o descobridor da Flórida: Lopez de Gomara disseque o reino do diabo era situado em uma ilha- do Mar dos Cará́bas.

Maiores detalhes sôbre êste assunto o leitor pode encontrar nos seguintes trabalhos: Leonardo Olschki, Storia Letteraria delle Scoperte Geografiche, Firenze, 1939; Luís Weckman, A Idade Média' na conquista da América, "Revista de História", volume. 18 , páginas 327 . 342 .
} 
sua irresponsabilidade total, como historiador. Melhor será que o notável historiador contemporâneo não procure incidir na mesma. pecha, com que pretende amesquinhar a memória de seu predecessor.

De tudo que acabamos de expor, chegamos sem o menor esfôrço a esta dura realidade: o erudito historiador português, Padre Serafim Leite, não se sente muito seguro nas suas afirmativas vi-. sando emprestar ao Padre Manuel da Nóbrega o privilégio de único. fundador de São Paulo de Piratininga, de vez que o que mais o. preocupa não é a verdade histórica, mas sim dar expansão à uma exagerada vaidade nacional. Tanto isso é verdade que, com espanto geral de seleto auditório, na terceira sessão plenária do Congresso de História realizado nesta Metrópole, a 10 de setembro do. corrente ano, declarou textualmente que "há paixão nas discussões (sôbre a fundação de São Paulo) "e paixão por paixão, a mim basta a de Nóbrega".

Pode-se admitir que o historiador como homem que é, ìntimamente se deixe conduzir por paixões, mas que as venha confessar em público, num congresso de história e adote isso como paradigma do seu processo de cuidar de história, é simplesmente de. estarrecer!

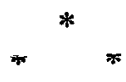

No dia 8 de setembro do ano em curso, o papa Pio XII atri- . buiu ao Padre Manuel da Nóbrega a fundação de São Paulo. Não. fêz, porém, essa declaração ex-cathedra, isto é, como chefe da Igreja, mas sim louvando-se em informações do Padre Serafim Leite, conforme noticiaram os jornais de Roma.

Mesmo que falasse ex-cathedra, as suas palavras não teriam valor, porque não nos consta que Sua Santidade se dedique ao estudo da história do nosso país. E depois, já se foi o tempo em que os papas tudo nos impunham, à semelhança de Alexandre VI que dividiu o mundo em duas partes, dando uma à Portugal e outra à Espanha, como quem parte uma melancia.

Outubro de 1954.

T. O. MARCONDES DE SOUZA

Da Sociedade de Estudos Históricos, do Instituto Histórico. e Geográfico de São Paulo. 